\title{
A proteção ambiental e a gestão compartilhada: um estudo de caso na Região Metropolitana de Natal
}

\author{
Environmental protection and shared management: \\ a case study in the Metropolitan Region of Natal
}

Raquel Maria da Costa Silveira ${ }^{[l]}$

Fábio Fonseca Figueiredo ${ }^{[I]}$ Jelisse Vieira Gomes Almeida ${ }^{[I I I]}$

\section{Resumo}

Este trabalho possui como objetivo refletir acerca da relação entre a Política Nacional de Resíduos Sólidos e o Estatuto da Metrópole, compreendendo as implicações e os desafios previstos nessas normas para as regiões metropolitanas no Brasil. 0 compartilhamento de soluções voltadas à preservação ambiental requer a pactuação entre diferentes atores políticos e sociais, o que, por vezes, cria obstáculos à existência de uma política efetiva. Nesse sentido, foi realizado um estudo de caso na Região Metropolitana de Natal (RMN), investigando-se, especificamente, a gestão compartilhada dos resíduos sólidos a partir da lei 12.305/2010. 0 estudo apontou para a ausência de cooperação na gestão dos resíduos sólidos no âmbito da RMN, apresentando-se, ainda, um cenário de descumprimento da norma de direito ambiental.

Palavras-chave: planejamento e gestão ambiental; território metropolitano; proteção ambiental; regiões metropolitanas; gestão de resíduos sólidos.

\begin{abstract}
In this paper, we aim to reflect on the relationship between the National Solid Waste Policy and the Metropolis Statute in order to understand the implications and challenges foreseen in these standards for the metropolitan regions in Brazil. Sharing solutions targeted at environmental preservation requires an agreement between different political and social actors, which sometimes creates obstacles to the existence of an effective policy. In this sense, we carried out a case study in the Metropolitan Region of Natal, in which we investigated, specifically, the shared management of solid waste in light of the federal law 12305/2010. The study showed lack of cooperation in the management of solid waste in the Metropolitan Region of Natal and revealed a scenario of noncompliance with the environmental law.
\end{abstract}

Keywords: environmental planning and management; metropolitan territory; environmental protection; metropolitan regions; solid waste management. 


\section{Introdução}

A cidade constitui-se como "meio, condição e produto da sociedade" (Bernardelli, 2010). Partindo-se de tal pressuposto, faz-se necessário atentar às transformações ocorridas nas metrópoles brasileiras tendo como agravante a intensa urbanização sofrida pelo País nas últimas décadas (IBGE, 2010).

As formas de planejamento e gestão contemporâneas com base na participação popular e na articulação entre os diversos agentes envolvidos nesse processo (Estado, mercado e sociedade) podem contribuir para o fomento dos ideais de reforma urbana e para a diminuição dos impactos da crescente urbanização. Paradoxalmente a essa questão, o quadro institucional urbano brasileiro pode ser caracterizado por uma "desgovernança" (Ribeiro e Orlando Junior, 2007), estando nas metrópoles a concentração dos efeitos mais dramáticos da complicada crise urbana e ambiental atravessada.

Com a Constituição Federal de 1988, a questão ambiental ganhou foco, sendo consagrado o meio ambiente ecologicamente equilibrado como direito fundamental. Isso implica dizer que o ordenamento jurídico brasileiro atribui ao equilíbrio ambiental função basilar na sociedade, tendo em vista sua relevância no que se refere à garantia do princípio da dignidade da pessoa humana e do bem-estar individual e coletivo.

As mudanças oportunizadas pela Constituição Federal que, no dizer de Silva (2013) possui caráter eminentemente ambientalista, visaram institucionalizar a política sobre meio ambiente no Brasil. Assim, a nova disposição constitucional acarretou a urgência por uma nova ordem ambiental pressupondo o engajamento da sociedade civil na tomada de decisões e o desenvolvimento de políticas públicas para que os efeitos nocivos ao meio ambiente sejam minimizados (Guerra, 2010).

Tendo em vista que "todo e qualquer bem essencial à sadia qualidade da vida humana e de uso comum do povo tem característica de bem ambiental" (Guerra e Guerra, 2012), os estudos sobre meio ambiente ganharam relevância do ponto de vista jurídico, social e econômico. Assim, surge o Direito Ambiental como ramo autônomo de Direito Público, com o objetivo de discutir e elaborar mecanismos formais para efetivar a adoção de medidas protetivas do meio ambiente, a fim de evitar ações de degradação ambiental e assegurar o desenvolvimento em sua forma sustentável.

0 marco legal para o desenvolvimento de políticas públicas para o meio ambiente no Brasil ocorreu no ano de 1981 por meio da criação da Política Nacional de Meio Ambiente (lei n. 6.938/1981), tendo por objetivo preservação, melhoria e recuperação da qualidade ambiental propícia à vida, além de contemplar diretrizes gerais com vistas a aliar as políticas públicas para o meio ambiente entre entes federados.

No que se refere às diversas problemáticas ambientais existentes, "os graves problemas de escassez de água (em quantidade e qualidade) e de disposição do lixo, associados aos inegáveis efeitos das mudanças climáticas" (Duarte, 2015, p. 1) são elencados como as questões mais preocupantes do ponto de vista social e ambiental.

Nesse sentido, dentro da perspectiva ambiental, a temática dos resíduos sólidos vem adquirindo maior visibilidade nas agendas de governo pela necessidade urgente de soluções 
sustentáveis especialmente em regiões metropolitanas, tendo em vista a concentração populacional característica dessas regiões, o que demanda sistemas de gestão cada vez mais abrangentes e eficientes.

Diante disso, após cerca de vinte anos de discussão, a lei n. 12.305/2010 instituiu a Política Nacional de Resíduos Sólidos (PNRS), com o objetivo de enfrentar as consequências sociais, econômicas e ambientais do manejo de resíduos sólidos sem prévio e adequado planejamento técnico. Para tanto, a legislação em análise impõe novos modelos de gestão e gerenciamento dos resíduos em municípios pertencentes às Regiões Metropolitanas em prol da redução dos impactos sociais e ambientais decorrentes dessa problemática em meio urbano.

Ressalta-se que, a despeito de preceder a vigência do próprio Estatuto da Metrópole, a lei 12.305/2010 apresenta preocupação explícita com a gestão metropolitana dos resíduos sólidos. A partir das diretrizes dessa norma, o processo de gestão deve ser compartilhado, devendo esta pautar-se na adoção de modelos baseados na prevenção da geração de resíduos e no tratamento dos materiais recicláveis a partir da coleta seletiva realizada por catadores.

A gestão dos resíduos sólidos é, portanto, uma das questões urbanas que requer um planejamento partilhado entre os entes locais. Ocorre que, apesar das prescrições legais, 0 cenário existente aponta para o descaso com a gestão dos resíduos até mesmo em nível local. É justamente por tais aspectos que se faz necessário analisar a efetividade da prescrição legal em nível metropolitano.
Em função da necessidade do estabelecimento de uma gestão metropolitana no Brasil para essa e outras temáticas, a lei n. 13.089/2015 instituiu o Estatuto da Metrópole, trazendo um conjunto de diretrizes para o planejamento, a gestão e a execução das funções públicas de interesse comum em regiões metropolitanas e em aglomerações urbanas instituídas pelos entes estaduais. Diante disso, o presente trabalho discutirá a problemática do planejamento e da gestão ambiental no território metropolitano. Objetiva-se refletir acerca da relação entre a Política Nacional de Resíduos Sólidos e o Estatuto da Metrópole, compreendendo as implicações e os desafios previstos nessas normas para as regiões metropolitanas no Brasil.

Para tanto, realizou-se um estudo de caso na Região Metropolitana de Natal (RMN), investigando-se, especificamente, a gestão compartilhada dos resíduos sólidos a partir da lei 12.305/2010. Para a realização da pesquisa, foi considerado, em um momento inicial, o indicador referente ao percentual da população em domicílios sem coleta de lixo (Ipea, 2015), o qual foi analisado em conjunto com o contexto atual do planejamento e da gestão dos resíduos sólidos nos quatorze municípios que compõem a Região Metropolitana de Natal, a partir de dados coletados de forma secundária, bem como por meio de entrevistas com gestores responsáveis pela política e da participação em audiências públicas em 2016, período de atualização do Plano Estadual de Resíduos Sólidos do Rio Grande do Norte. 


\section{Os desafios da gestão metropolitana no Brasil a partir do regramento estabelecido no estatuto da metrópole}

Conforme o Censo 2010 do Instituto Brasileiro de Geografia e Estatística (IBGE), é possível observar a mudança no perfil da relação "urbano-rural" no País, uma vez que, entre os anos de 1950 e 2010, houve um aumento de, aproximadamente, $48 \%$ da população urbana nacional.

Nesse contexto, os desafios metropolitanos relacionados ao aumento da pobreza, à segregação social e territorial, à deterioração do meio ambiente e da qualidade de vida, ao aumento da violência e da criminalidade, para mencionar alguns desafios mais urgentes, perpassam as fronteiras político-administrativas (Frey, 2012).

A proximidade dos centros urbanos, tendo como agravante a crescente urbanização caracterizada no País, acarreta a consolidação de problemas de cunho estrutural nas cidades, tendo em vista o aumento de demandas do ponto de vista urbano e social, bem como a dificultosa habilidade dos gestores públicos locais em solucionar tais problemas. Assim, o planejamento surge, nesse cenário, como uma ferramenta capaz de minimizar os impactos causados pelo fenômeno da urbanização, contribuindo para a promoção de uma cidade equilibrada no que se refere ao crescimento e à qualidade de vida da população.

Segundo Souza (2000), o termo planejamento está relacionado a eventos futuros, na medida em que tenta prever a evolução de um fenômeno, simulando os desdobramentos de um processo, no que diz respeito a problemas e soluções. Já a gestão significa administrar as necessidades e os recursos imediatos. Sendo assim, entende-se que ambos os instrumentos são distintos, porém complementares.

No tocante ao planejamento urbano, a Constituição Federal de 1988, em seus artigos 182 e 183, apresenta preceitos inovadores no que diz respeito à política urbana no Brasil. 0 mencionado artigo dispõe que as cidades com mais de 20 mil habitantes possuem a obrigatoriedade da elaboração de Planos Diretores, sendo função do poder público municipal a execução da política de desenvolvimento urbano que tem como "objetivo ordenar o pleno desenvolvimento das funções sociais da cidade e garantir o bem-estar de seus habitantes" (Brasil, 1988).

No ano de 2001, entrou em vigor, no Brasil, o Estatuto das Cidades com o objetivo de impulsionar a adoção de programas e projetos de reforma urbana no âmbito dos governos locais. Assim, os governos locais teriam à sua disposição um conjunto de instrumentos legais, urbanísticos e fiscal-financeiros necessários à adoção de políticas regulatórias, redistributivas e de democratização da propriedade urbana e do acesso aos serviços e equipamentos de consumo coletivo (Ribeiro e Santos Jr., 2007).

No ano de 2015, foi instituído o Estatuto da Metrópole, estabelecendo diretrizes gerais para o planejamento, a gestão e a execução das funções públicas de interesse comum nos territórios das regiões metropolitanas e em aglomerações urbanas instituídas pelos estados, normas gerais sobre o plano de desenvolvimento urbano integrado, outros instrumentos e critérios para o apoio da União a ações que 
envolvam governança interfederativa no campo do desenvolvimento urbano.

É importante esclarecer que tais ações públicas de interesse comum são aquelas que perpassam as fronteiras de um município, ou seja, problemáticas urbanas que um município não pode solucionar sozinho ou que impactam de forma direta em municípios vizinhos, como, por exemplo, transporte público, saúde, educação, saneamento, moradia e meio ambiente.

Sendo assim, torna-se possível afirmar que o Estatuto da Metrópole tem seu fundamento principal na necessidade de criação de uma governança interfederativa, em que se estabelecem conceitos, regras, princípios e instrumentos para o alcance da colaboração na esfera metropolitana a partir do "compartilhamento de responsabilidades e ações entre entes da Federação em termos de organização, planejamento e execução de funções públicas de interesse comum" (Brasil, 2015).

Instrumentos urbanísticos regulatórios, como os Planos Diretores, o Estatuto das Cidades e o Estatuto das Metrópoles, possibilitam a efetivação de uma reforma urbana orientada para a função social da cidade e da propriedade, sendo possível a promoção do bem-estar da população e o avanço das prerrogativas estabelecidas no planejamento e gestão urbanos. Contudo, além dos entraves já conhecidos, como a dificuldade de articulação entre os agentes envolvidos no âmbito da gestão pública e as características inerentes a cada cidade, há a intervenção da globalização como processo inevitável, trazendo consequências imediatas para as cidades.

É importante considerar as transformações estruturais ocorridas nas cidades contemporâneas, estando a evolução tecnológica no centro dessa discussão, em que há a formulação de novos paradigmas com a inovação como uma constante no cenário urbano. Diante desse novo desafio, surgem novas formas de gestão urbana, sendo importante considerar a atuação desses atores em redes e especificar quais são seus papéis.

Partindo da transformação das sociedades pelos processos de globalização e informacionalização e levando em consideração que tais transformações possuem uma dimensão espacial, Castells e Borja (1996) afirmam que a cidade passa a ser encarada como ator político, uma vez que promove acordos e associações, assumindo responsabilidades diante da sociedade e do poder público, representando uma espécie de articulador entre as diversas instâncias da sociedade civil, agentes privados e Estado.

No seio dessa discussão, Ribeiro e Santos Junior (2007, p. 26) afirmam que o período de transição atravessado pelas metrópoles brasileiras remete a consequências como a "ausência de um sistema de governabilidade urbana e desestruturação do regime de bem-estar social". Dessa forma, é importante considerar que, naqueles territórios abrangidos por regiões metropolitanas, qualquer estratégia em prol do bem-estar urbano bem como as demais ações públicas terão que considerar o contexto territorial em que se inserem e a necessidade de que os seus entes se configurem como atores políticos capazes de promover e concretizar a governança interfederativa.

Frise-se que o território é produto das ações e transformações realizadas por agentes sociais diversos. Assim, tem-se que a própria formação e composição de regiões metropolitanas no Brasil tornaram-se um paradoxo por 
representar, muitas vezes, a criação de um arranjo territorial a partir de critérios políticos, 0 que, por sua vez, torna dificultosa a criação de uma cooperação entre os entes.

No Brasil, as regiões metropolitanas foram criadas no ano de 1973, por meio da lei complementar n. 14, conforme a Constituição de 1967, vigente na época. Contudo, com a homologação da Constituição Federal de 1988, a responsabilidade pela criação e organização das regiões metropolitanas, aglomerações urbanas e microrregiões, constituídas por agrupamentos de municípios limítrofes foram transferidas para os estados, com 0 objetivo de integrar a organização, o planejamento e a execução de funções públicas de interesse comum.

Em linhas gerais, uma região metropolitana é uma área formada por vários municípios que apresentam uma estrutura ou aglomeração urbana interligada. 0 fenômeno da conurbação, característica das regiões metropolitanas brasileiras, consiste na fusão de áreas urbanas a partir de uma expansão espacial dos núcleos urbanos (Villaça, 1997), inclusive no que diz respeito às relações socioeconômicas locais.

A união dos municípios com o propósito de compartilhar a busca de solução de problemas e a defesa de interesses comuns é uma estratégia eficiente na recomposição do planejamento e da gestão metropolitana, pois aumenta o seu poder e as suas chances de sucesso nas negociações com as instâncias burocráticas superiores para o atendimento de suas reivindicações (Clementino, 2003, p. 34).

Entretanto há um desvirtuamento da potencialidade de resolução dos problemas urbanos pelo viés da colaboração intermunicipal. Segundo o IBGE (2010), no Brasil existem 37 regiões metropolitanas oficialmente instituídas, contudo nem todas apresentam estruturas socioespaciais inerentes às regiões metropolitanas, ou seja, não apresentam razões técnicas para serem concebidas como tais.

0 fato é que o estreitamento das relações político-administrativas com o ingresso de um município na região metropolitana oportuniza investimentos, federais ou privados, além de elevar o status de um município nela inserido do ponto de vista político e econômico (Ribeiro e Santos Junior, 2007).

Desse modo, o cenário da formação das regiões metropolitanas no Brasil expõe a problemática de gestão envolta nesses territórios: o fator político determina a inserção de municípios nesses arranjos territoriais formais, refletindo-se, igualmente, na existência de colaboração entre os entes. Nesse contexto, Clementino e Almeida (2015) afirmam a inexistência de consciência e identidade metropolitanas capazes de impulsionar as articulações no que diz respeito às ações públicas de interesse comum.

Para além da ausência de uma identidade, Gouvêa (2009) destaca que as regiões metropolitanas brasileiras carecem de arranjos institucionalizados para efetivar a formulação, a implementação e o controle de políticas públicas plurimunicipais, ou seja, políticas que, devido as suas características estratégicas, como desenvolvimento urbano, transporte e meio ambiente, não têm como serem solucionadas nos limites do município.

Diante de tal contexto, a lei federal n. 13.089/2015, denominada Estatuto da Metrópole surgiu como uma tentativa de incentivar "a cooperação interfederativa entre a união, estados e municípios no fomento às ações voltadas para o desenvolvimento urbano 
das RMs" (Clementino, 2016, p. 11). Essa norma determina a necessidade de promoção da governança interfederativa entre o estado e os municípios inclusos em regiões metropolitanas ou em aglomerações urbanas. Tal governança, por sua vez, deverá pautar-se nos seguintes princípios: prevalência do interesse comum sobre o local; compartilhamento de responsabilidades para a promoção do desenvolvimento urbano integrado; autonomia dos entes da Federação; observância das peculiaridades regionais e locais; gestão democrática da cidade; efetividade no uso dos recursos públicos, bem como na busca do desenvolvimento sustentável.

Dentre tais princípios elencados, a necessidade de compartilhamento de responsabilidades para a promoção do desenvolvimento urbano integrado requer a busca por soluções pactuadas, as quais promovam a articulação entre as políticas públicas para 0 alcance dos interesses comuns. Trata-se de uma perspectiva que considera o território metropolitano como elemento fundamental para a efetividade das políticas públicas. Entretanto, por ser o território produto dos agentes sociais, a norma em comento surgiu, justamente, como forma de estabelecer os princípios e as diretrizes que devem orientar as práticas com vistas à cooperação, consolidando um paradigma pautado na governança, a despeito das habituais disputas e interesses políticos.

Na prática, aponta-se a ausência de mecanismos fixos e de práticas constantes que se fundamentem em ações coordenadas e cooperadas entre entes que compõem tais arranjos (Clementino e Almeida, 2015). 0 fato é que "as alianças e a cooperação institucional entre as coletividades locais (a metrópole é uma delas) são importantes para que certas políticas mudem de escala, para que estratégias comuns de desenvolvimento sejam executadas, para que a promoção da área metropolitana seja eficaz" (ibid., p. 212).

0 fato é que a criação da norma, por si, não alcança os conflitos que envolvem diversos territórios locais e, portanto, distintos interesses políticos. No Brasil, a inexistência de uma adequada e efetiva estrutura de planejamento e de mecanismos permanentes de financiamento dos problemas comuns oferece limites para a existência de uma gestão compartiIhada, persistindo "um vazio institucional no que diz respeito à governança compartilhada" (ibid., p. 216).

A despeito dos preceitos dessa norma, 0 cenário de ausência de coordenação no planejamento e na gestão das políticas públicas é o indicador mais fiel a ser utilizado na presente discussão. É possível, dessa forma, indicar diversas áreas nas quais o descompasso na solução dos problemas comuns se impõe, entre elas, pode-se apontar, justamente, a gestão dos resíduos sólidos urbanos.

\section{Aspectos gerais da política nacional de resíduos sólidos e suas implicações nas regiões metropolitanas}

A gestão dos resíduos sólidos no Brasil, durante muitos anos, esteve à margem das agendas governamentais, sendo realizada conforme ações inarticuladas e não regulamentas. Nesse sentido, a Política Nacional de Resíduos Sólidos (lei n. 12.305/2010) representa um marco para a proteção ao meio ambiente do ponto 
de vista jurídico, social e econômico no País, uma vez que impõe um novo modelo de gestão com base na descentralização de políticas públicas, atribuindo aos municípios a gestão dos resíduos sólidos gerados em seus respectivos territórios.

Considera-se como premissa da PNRS o compartilhamento de soluções integradas para os resíduos sólidos, tendo como base a colaboração entre os municípios. Essa legislação foi estruturada mediante intensos debates entre os diversos atores públicos e privados interessados na problemática socioambiental em torno da gestão dos resíduos sólidos (sociedade civil, segmentos empresariais, entidades ambientalistas, representantes da indústria de reciclagem, catadores de materiais recicláveis e especialistas na gestão dos resíduos).

Tal aspecto deu base para a criação do conceito de responsabilidade compartilhada pelo ciclo de vida dos produtos, definida, no art. $3^{\circ}$, XVII da PNRS, como um conjunto de atribuições individualizadas e encadeadas dos fabricantes, importadores, distribuidores e comerciantes, dos consumidores e dos titulares dos serviços públicos de limpeza urbana e de manejo dos resíduos sólidos, para minimizar o volume de resíduos sólidos e rejeitos gerados, bem como para reduzir os impactos causados à saúde humana e à qualidade ambiental decorrentes do ciclo de vida dos produtos.

0 compartilhamento, por sua vez, também surge na PNRS, ao explicitar-se a necessidade de promoção da integração da organização, do planejamento e da execução das funções públicas de interesse comum relacionadas à gestão dos resíduos sólidos nas regiões metropolitanas pelos entes estaduais (art. 11, I, PNRS).
0 ente federado local, conforme dispõe a lei 12.305 , possui atribuições específicas no que diz respeito ao planejamento e à gestão dos resíduos sólidos em seus territórios, priorizando a gestão integrada desses materiais, o que consiste no conjunto de ações voltadas para a busca de soluções para os resíduos, considerando-se as dimensões política, econômica, ambiental, cultural e social, com controle social e sob a premissa do desenvolvimento sustentável (Brasil, 2010).

Cabe também aos municípios a elaboração de planos municipais de gestão integrada de resíduos sólidos, a disposição final dos rejeitos de forma adequada do ponto de vista ambiental, a erradicação dos lixões e o estabelecimento e consolidação de um sistema de coleta seletiva municipal. 0 cumprimento desses requisitos é fundamental, inclusive, no que se refere ao acesso aos recursos da União destinados aos serviços de limpeza pública e manejo dos resíduos sólidos.

A demanda por amenizar os impactos causados pelo inadequado gerenciamento dos resíduos sólidos implicou a adoção de prazos para que os municípios implementassem as ações dispostas na legislação específica. Promulgada em 2010, a PNRS estabeleceu que, até o ano de 2012, todos os municípios brasileiros deveriam ter elaborado seus respectivos planos municipais de gestão integrada de resíduos sólidos e que, até 2014, os locais de armazenamento que não estivessem adequados do ponto de vista ambiental deveriam ser erradicados. Embora os prazos fixados em lei estivessem coerentes no plano teórico, com o passar do tempo, os municípios brasileiros não conseguiram adaptar-se à nova realidade imposta pela PNRS, acarretando no descumprimento 
em massa dos prazos instituídos. Silveira e Clementino (2017, p. 9) apontam que "a Política Nacional de Resíduos Sólidos, ao fixar os prazos, teria sido mais otimista do que realista em vista da condição econômica e administrativa dos municípios brasileiros", sendo citados, principalmente, fatores como dificuldades financeiras e incapacidades técnicas para a implementação das disposições da PNRS.

Para além do enfoque local, faz-se necessário apresentar considerações acerca das disposições legais em torno da gestão dos resíduos sólidos na esfera metropolitana, tendo em vista que, sob o olhar metropolitano, as problemáticas ampliam-se perante sua dimensão territorial e populacional.

0 padrão do processo de metropolização no Brasil é caracterizado, conforme Grostein (2001), pela insustentabilidade dos processos de expansão e transformação urbana, estando os impactos provenientes do ineficaz gerenciamento dos resíduos sólidos refletidos de forma incisiva na qualidade de vida da população.

Diante disso, nos termos da lei 12.305/2010, caberá aos entes estaduais a promoção da integração, da organização, do planejamento e da execução das funções públicas de interesse comum relacionadas à gestão dos resíduos sólidos nas regiões metropolitanas. Desse modo, os planos estaduais de resíduos sólidos deverão apresentar, dentre outros elementos mínimos, as diretrizes para o planejamento e demais atividades de gestão de resíduos sólidos de regiões metropolitanas, aglomerações urbanas e microrregiões (art. 17, IX, PNRS).

Em essência, as regiões metropolitanas foram criadas com o objetivo de gerir problemas urbanos que ultrapassem os limites territoriais e capacidades municipais, tendo como base a colaboração intermunicipal. Nesse sentido, a PNRS em seu artigo 11, inciso I, dispõe que é de competência dos entes estaduais a promoção, organização, planejamento e execução das funções públicas de interesse comum relacionadas à gestão dos resíduos.

Cumpre destacar, ainda, que a PNRS apresenta, como um de seus instrumentos, 0 incentivo à adoção de consórcios ou de outras formas de cooperação entre os entes federados, com vistas à elevação das escalas de aproveitamento e à redução dos custos envolvidos (art. $8^{\circ}$, XIX, PNRS). A consolidação dos consórcios no que diz respeito à gestão de resíduos sólidos corrobora para o aprimoramento do estudo, do acompanhamento e do diagnóstico de soluções para as problemáticas regionais de cunho ambiental, sendo uma prioridade do Estado apoiar as iniciativas de soluções consorciadas, conforme dispõe a legislação.

Mediante os dispositivos previstos na PNRS, portanto, o planejamento e a gestão dos resíduos sólidos urbanos devem se constituir como ação coordenada, pautando-se, igualmente, na cooperação entre os municípios que compõem regiões metropolitanas. Entretanto, 0 histórico de descaso com a gestão dos resíduos e a ausência de alianças e de cooperação institucional entre as coletividades locais (Clementino e Almeida, 2015) constituem-se como entraves à realização das diretrizes dessa norma.

Diante da discussão realizada, a seguir serão discutidos os resultados do estudo de caso realizado na Região Metropolitana de Natal, por meio do qual se refletiu acerca da relação entre a Política Nacional de Resíduos Sólidos e o Estatuto da Metrópole, compreendendo as implicações e os desafios previstos nessas normas. 


\section{0 desafio da cooperação: a gestão dos resíduos sólidos na Região Metropolitana de Natal}

\begin{abstract}
A Região Metropolitana de Natal (RMN) foi criada, em 1997, por meio da Lei Complementar Estadual (LCE) n. 152. Inicialmente, era composta por cinco municípios: Macaíba, Extremoz, São Gonçalo do Amarante, Ceará-Mirim, Parnamirim e Natal. Atualmente, o arranjo conta com catorze entes, tendo sido acrescentados: São José de Mipibu, Nísia Floresta (LCE n. 221/2002), Monte Alegre (LCE n. 315/2005), Vera Cruz (LCE n. 391/2009), Maxaranguape (LCE n. 485/2013), lelmo Marinho (LCE n. 540/2015), Arês e Goianinha (LCE n. 559/2015).
\end{abstract}

Sob o ponto de vista regional, a RMN é responsável pela geração de, aproximadamente, $43,5 \%$ do resíduo gerado no estado do Rio Grande do Norte, ocupando o primeiro lugar no ranking de geração de resíduos com base na produção per capita, ${ }^{1}$ segundo informações do Plano Estadual de Resíduos Sólidos do RN no ano de 2015 (Pers, 2015).

De acordo com Pessoa (2012), a gestão dos resíduos sólidos na Região Metropolitana de Natal se caracteriza como um grande desafio. Até 2004, os resíduos sólidos gerados nos municípios eram destinados a lixões. A partir do referido ano, com a criação do denominado aterro sanitário metropolitano, seis dos dez municípios que formavam a RMN iniciaram uma nova forma de destinação. A limpeza urbana era precária, inexistindo uma política integrada de gerenciamento de resíduos sólidos. Considerando esse panorama inicial, torna-se necessário estudar a relação entre a gestão integrada dos resíduos sólidos na RMN e a busca compartilhada pela solução de problemas ambientais e urbanos a partir do desenho metropolitano.

Para tanto, inicialmente, foi analisado o percentual da população em domicílios sem coleta de lixo nos municípios que compõem a RMN. Utilizando-se como parâmetro os percentuais estaduais $(2,49 \%)$ e nacional $(2,98 \%)$, foi possível denotar que, em 2010, os municípios de Natal, Parnamirim, Vera Cruz e Ceará Mirim se destacaram por seu baixo percentual de indivíduos em domicílios sem coleta de lixo, existindo dez municípios com taxa acima do parâmetro de análise. 0 município de Maxaranguape, por exemplo, apresentou 20,15\% dos seus munícipes sem acesso à coleta domiciliar, o que pode ser verificado no Quadro 1.

A partir dos dados do Ipea (2015), comparando-se os resultados obtidos em 2000 e 2010, é possível verificar que alguns municípios apresentaram resultado inverso à tendência de redução desse percentual. Esse foi o caso de Arês e Maxaraguape: o primeiro apresentou crescimento de 3,54\% para 5,2\% e no segundo, por sua vez, o aumento foi de 6,29\% para $20,15 \%$.

A análise dos dados torna possível verificar que parte da população da RMN sequer possui acesso ao serviço essencial básico de coleta de lixo. Além disso, o elevado percentual apresentado pelo município de Maxaranguape, em relação aos demais entes, representa dois aspectos que merecem destaque: (1) a vulnerabilidade socioambiental a que estão submetidos os cidadãos (Ipea, 2015) e (2) a disparidade no que tange à capacidade de prestação de um serviço de forma efetiva entre municípios que compõem um mesmo arranjo territorial, o que 


\section{Quadro 1 - Percentual da população em domicílios sem coleta de lixo nos municípios da RMN}

\begin{tabular}{|l|c|}
\hline Municípios da RMN & $\begin{array}{c}\text { \% da população em domicílios } \\
\text { sem coleta de lixo (2010) }\end{array}$ \\
\hline Natal (RN) & 1,18 \\
Parnamirim (RN) & 1,19 \\
Vera Cruz (RN) & 1,5 \\
Ceará-Mirim (RN) & 1,95 \\
Goianinha (RN) & 3,19 \\
São José de Mipibu (RN) & 3,72 \\
Monte Alegre (RN) & 4,31 \\
Nísia Floresta (RN) & 4,44 \\
lelmo Marinho (RN) & 4,53 \\
Macaíba (RN) & 4,84 \\
Arês (RN) & 5,2 \\
São Gonçalo do Amarante (RN) & 7,65 \\
Extremoz (RN) & 9,2 \\
Maxaranguape (RN) & 20,15 \\
\hline
\end{tabular}

Fonte: elaborado pelos autores com base em IPEA (2015).

evidencia a inexistência de uma gestão compartilhada de uma problemática que lhes é comum.

Ao passo em que foi possível realizar a análise de tal dado, verificou-se ser essencial estudar o cumprimento da lei 12.305/2010 na $\mathrm{RMN}$, considerando, igualmente, as diretrizes do Estatuto da Metrópole. Nesse momento, combinou-se a coleta de dados secundários com as informações de Silveira, Ferreira e Nunes (2017), tornando-se possível a obtenção de um panorama geral da gestão dos resíduos.

A partir da pesquisa realizada, foi possível constatar a existência de um cenário que ainda se aproxima do contexto apontado por Pessoa (2012). 0 fato é que sete, dentre os catorze municípios que compõem a RMN, ainda destinam seus resíduos a lixões. Em 2012, seis dos dez municípios que compunham a RMN destinavam seus resíduos em aterro sanitário. Cinco anos após o estudo realizado por Pessoa (ibid.), somente sete municípios destinam adequadamente o material coletado. Nesse aspecto, novamente, os municípios de Maxaranguape e Arês ganham destaque, visto que possuem como destinação final dos seus resíduos áreas a céu aberto.

Conforme a tabela que segue, Nísia Floresta, Monte Alegre, São José de Mipibu, Goianinha e Vera Cruz também indicaram como destinação final dos materiais coletados os lixões, constituindo-se, igualmente, como municípios que apresentaram percentuais elevados de indivíduos sem acesso à coleta (se comparados aos índices estadual e nacional). 
Quadro 2 - Panorama geral da gestão dos resíduos sólidos na RMN

\begin{tabular}{|l|c|c|c|}
\hline \multicolumn{1}{|c|}{ Municípios da RMN } & $\begin{array}{c}\text { \% da população } \\
\text { em domicílios sem coleta } \\
\text { de lixo (2010) }\end{array}$ & Destinação Final & $\begin{array}{c}\text { Existência de programa } \\
\text { de coleta seletiva }\end{array}$ \\
\hline Natal & 1,18 & Aterro Sanitário & Não \\
Parnamirim & 1,19 & Aterro Sanitário & Sim \\
Vera Cruz & 1,5 & Lixão & Não \\
Ceará-Mirim & 1,95 & Aterro Sanitário & Não \\
Goianinha & 3,19 & Lixão & Não \\
São José de Mipibu & 3,72 & Lixão & Não \\
Monte Alegre & 4,31 & Lixão & Não \\
Nísia Floresta & 4,44 & Lixão & Não \\
lelmo Marinho & 4,53 & Aterro Sanitário & Sim \\
Macaíba & 4,84 & Aterro Sanitário & Não \\
Arês & 5,2 & Lixão & Não \\
São Gonçalo do Amarante & 7,65 & Aterro Sanitário & Não \\
Extremoz & 9,2 & Aterro Sanitário & Lixão \\
Maxaranguape & 20,15 & & \\
\hline
\end{tabular}

Fonte: elaborado pelos autores a partir dos dados da pesquisa e dos resultados apresentados por (2015) e Silveira et al. (2017).

Foi possível constatar que somente Natal, Vera Cruz e Arês oferecem o serviço de coleta seletiva dos materiais previamente segregados. A partir dos dados coletados, os resultados traçados na pesquisa foram representados no mapa que segue, apresentando o cenário da gestão dos resíduos sólidos urbanos, considerando o percentual da população em domicílios sem coleta de lixo, a destinação final dos resíduos e a realização de coleta seletiva.

Nesse sentido, o estudo realizado demonstrou a ocorrência de um tímido avanço no que tange ao cumprimento dos preceitos da PNRS pelos municípios que compõem a RMN se utilizarmos como parâmetro o contexto apontado por Pessoa (ibid.). Os municípios de Maxaranguape e Arês representam casos mais graves de descumprimento, com ressalva para a afirmação de realização da coleta seletiva por este último.

Municípios como São Gonçalo do Amarante, Extremoz, Macaíba e Ielmo Marinho, a despeito de ainda apresentarem percentual de indivíduos sem acesso à coleta que supera as taxas estadual e nacional, representaram um cenário intermediário, visto que afirmaram destinar corretamente os materiais coletados.

Essa contextualização geral realizada a partir dos dados coletados será utilizada, aqui, como base para a análise acerca da concretização da gestão compartilhada pelos municípios da RMN. A partir das informações apresentadas, foi possível constatar uma tentativa de pactuação por parte de sete dos catorze 
Figura 1 - Cenário da gestão dos resíduos sólidos urbanos na RMN, considerando o percentual da população em domicílios sem coleta de lixo, a destinação final dos resíduos e a realização de coleta seletiva

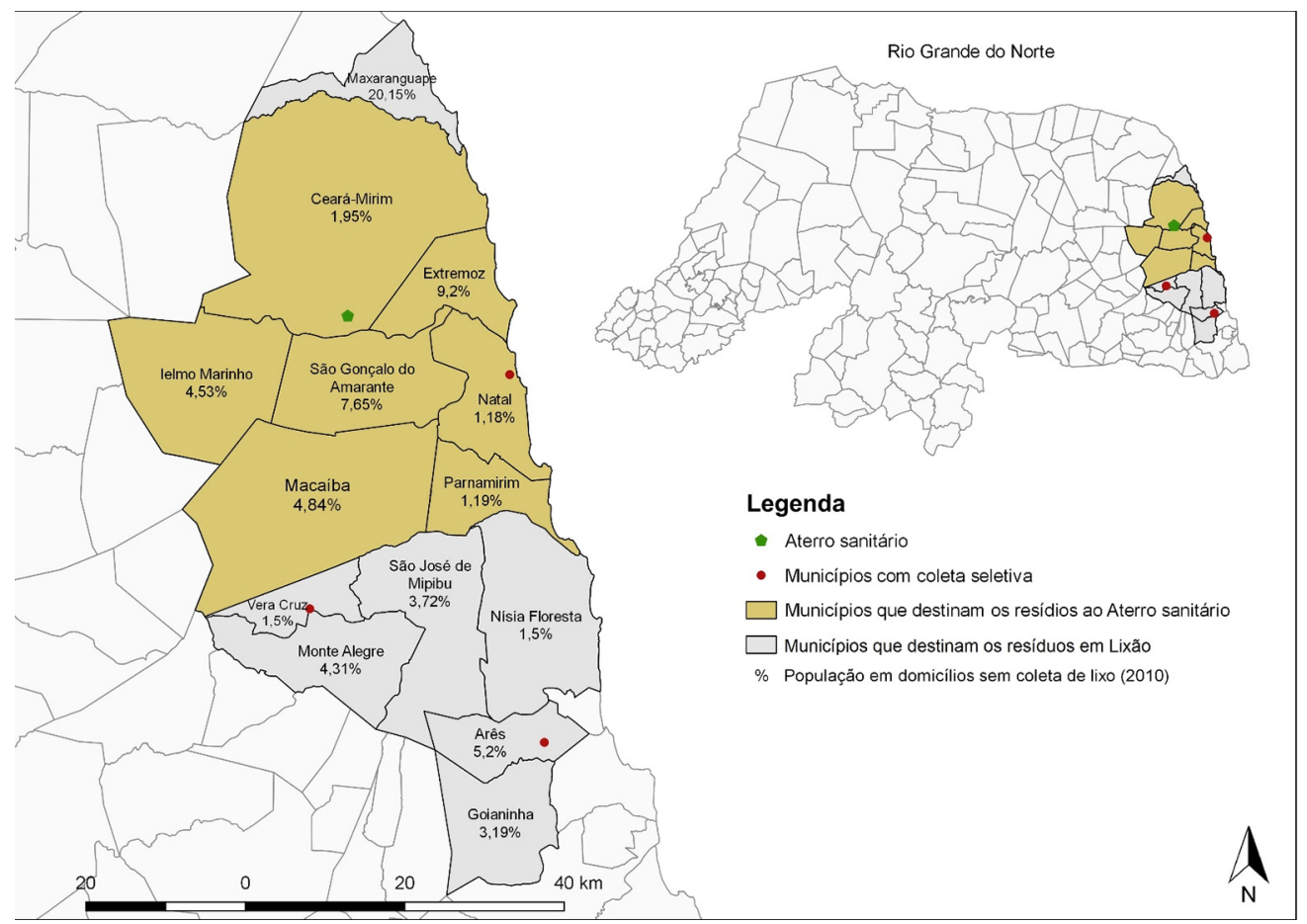

Fonte: elaborado pelos autores, 2017.

municípios. Entretanto, a solução compartilhada estava restrita à destinação final dos materiais ao aterro sanitário denominado metropolitano. Não foi constatado, portanto, diálogo amplo relativo aos demais aspectos que formam uma gestão integrada dos resíduos.

A partir da análise do mapa, é possível observar que a adequada disposição final dos resíduos somente foi verificada em municípios próximos à localização do aterro sanitário de Ceará Mirim, excetuando-se o caso de Maxaranguape que, mesmo estando vizinho ao local de disposição final ambientalmente correto, ainda mantem uma realidade de destinação inadequada. Os demais municípios, até mesmo pela distância em relação ao aterro, optam pelo descarte em lixões em função, principalmente, dos custos com o transporte do material.

Ressalte-se que, de acordo com a pesquisa realizada, o papel de indutor a ser realizado pelo governo estadual ainda é tímido no Rio Grande do Norte. Tal aspecto foi estudado a partir da participação nas audiências públicas realizadas, no ano de 2016, as quais foram realizadas em virtude da atualização do Plano Estadual de Gestão Integrada de Resíduos Sólidos. 
Conforme foi possível denotar, a atuação do governo do Rio Grande do Norte restringia-se à criação de arranjos regionais para a gestão dos resíduos pelos municípios. A despeito da sua competência para a criação de regiões metropolitanas, bem como da necessidade de que assuma o protagonismo na promoção da governança interfederativa (art. $3^{\circ}$, parágrafo único, lei 13.089/2015), o ente estadual apresentou, no Plano Estadual, regionalização distinta à atual formação institucional da RMN.

Em tal documento, Maxaranguape, Ceará-Mirim, Extremoz, lelmo Marinho, São Gonçalo do Amarante, Parnamirim, Macaíba e Natal são municípios que devem compor um único arranjo territorial para a destinação final dos resíduos para o aterro metropolitano. Já Vera Cruz, Nísia, São José de Mipibu, Monte Alegre e Arês compõem a região Agreste, devendo, portanto, ao final, apresentar pactuação diferenciada dos demais municípios metropolitanos para a gestão dos seus resíduos.

A explicação técnica apresentada pelo governo está pautada nas características dos municípios e na proximidade entre as cidades. Contudo, é necessário destacar que a fixação de uma regionalização distinta para entes integrantes de uma mesma região metropolitana, além de descompassar o planejamento e a gestão de problemas comuns, revela um território desarticulado, tendo-se o aspecto político como fundamento da composição da RMN, em detrimento dos critérios objetivos que deveriam pautar tais arranjos.

0 fato é que a ausência de cooperação entre entes municipais que compõem regiões metropolitanas, no Brasil, deve ser apontada como um problema de cunho político. Primeiro, porque inexiste uma estrutura de governo própria para os seus problemas, dependendo da viabilidade de negociações entre entes que, por vezes, não dialogam em função de questões político-partidárias. As regiões metropolitanas são, na verdade, "arranjos institucionais e territoriais "atípicos" do planejamento governamental e da gestão urbana" (Clementino e Almeida, 2015, p. 212). Segundo porque, muitas vezes, a composição inicial de tais arranjos e a posterior entrada de novos municípios rompem com a racionalidade que deve caracterizar uma região metropolitana, o que, como destacou Albuquerque Neta (2007) para o caso de Natal, confere margem para a introdução paulatina de novos municípios que não possuem características e identidade metropolitanas.

Nesse sentido, o estudo da gestão dos resíduos na RMN possibilita a visualização de um caso em que o arranjo territorial preestabelecido, ao invés de se configurar como facilitador para a efetivação da norma ambiental estudada (PNRS), revela o descompasso entre os seus entes. 0 governo estadual, por sua vez, no exercício de seu papel de coordenador e indutor da governança interfederativa, reconhece a inexistência e a inviabilidade física de cooperação entre os membros do arranjo, apontando, no caso da gestão dos resíduos, uma solução territorial que destoa da composição da região metropolitana, na contramão das disposições do Estatuto da Metrópole. Configura-se, portanto, um cenário em que o arranjo territorial não foi fator benéfico ao cumprimento dos fins legais da norma de direito ambiental.

Os municípios, por sua vez, a despeito de seu papel de ator político (Castells e Borja, 1996), vem, de forma geral, tratando a questão ambiental e, de forma específica, a gestão dos resíduos sólidos, como uma problemática 
puramente local. Desse modo, as soluções engendradas ignoram a capacidade de tais entes de realizar acordos e associações, distanciando-se da gestão compartilhada e do conceito de governança interfederativa.

0 presente estudo tornou possível compreender as implicações e os desafios previstos nas normas estudadas. Explicitou-se a ausência de diálogo entre os atores políticos na tomada de decisão e, consequentemente, de uma solução integrada e compartilhada para problemas ambientais comuns. Ainda destacou que, ao mesmo tempo que o território representa um elemento fundamental para a proteção do meio natural e para a efetividade da norma, 0 aspecto político que justifica a composição do arranjo territorial pode, por vezes, impedir a existência da cooperação.

\section{Considerações finais}

A partir do estudo de caso realizado, foi possível verificar, de um lado, a existência de um arranjo territorial institucionalizado que visa à solução de problemáticas comuns diversas, dentre elas, aquelas relacionadas à proteção ambiental. Por outro lado, verificou-se, a ausência de cooperação na gestão dos resíduos sólidos, apresentando-se, ainda, um cenário de descumprimento da norma de direito ambiental em estudo.

Tais resultados se configuram como indicador relevante na análise do território enquanto elemento fundamental para o acesso e a apropriação dos recursos naturais, bem como para a efetividade das normas ambientais.

A despeito da instituição de uma governança interfederativa entre entes que compõem arranjos metropolitanos - a partir do regramento do Estatuto da Metrópole, as diretrizes presentes na Política Nacional de Resíduos Sólidos permanecem sendo descumpridas na Região Metropolitana de Natal em virtude da ausência de colaboração por parte dos entes municipais e de coordenação pelo governo estadual.

Conforme exposto, os desafios impostos pela norma de direito ambiental estudada vêm sendo enfrentados apenas em nível local. Após a análise dos dados, evidenciou-se um cenário de descompasso da capacidade institucional apresentada pelos entes que compõem a RMN, o que se refletiu em um panorama heterogêneo da gestão de resíduos sólidos pelos municípios estudados.

A despeito da existência de um arranjo territorial institucionalizado para a criação de soluções compartilhadas, foi possível verificar a inexistência de uma cooperação ampla entre os quatorze membros, o que, por sua vez, poderia representar um fator fundamental para a efetividade dos aspectos estabelecidos pela PNRS e pelo Estatuto da Metrópole.

No caso da gestão dos resíduos sólidos na RMN, demonstrou-se tratar-se, portanto, de uma problemática ambiental que requer a pactuação de membros de um mesmo arranjo territorial institucionalizado, mas que, em virtude da diversidade de interesses e práticas, permanece buscando soluções individuais. 
[I] https://orcid.org/0000-0003-4560-1451

Universidade Federal do Rio Grande do Norte, Centro de Ciências Humanas, Letras e Artes, Programa de Pós-Graduação em Ciências Sociais. Natal, RN/Brasil.

raquelmcsilveira@hotmail.com

[II] https://orcid.org/0000-0002-3222-0230

Universidade Federal do Rio Grande do Norte, Grupo de Pesquisa Sociedade, Ambiente, Desenvolvimento. Natal, RN/Brasil.

ffabiof@yahoo.com

[III] https://orcid.org/0000-0002-8715-1340

Universidade Federal do Rio Grande do Norte, Centro de Ciências Humanas, Letras e Artes, Programa de Pós-Graduação em Estudos Urbanos e Regionais. Natal, RN/Brasil.

jelissevieira_@hotmail.com

\section{Nota}

(1) Dados do Pers-RN (2015) apontam para a geração de 430.550,30 toneladas de resíduos sólidos por ano.

\section{Referências}

ALBUQUERQUE NETA, T. C. de (2007). Desafios da governança no contexto da Região Metropolitana de Natal. In: $13^{\circ}$ ENCONTRO DE CIÊNCIAS SOCIAIS NORTE E NORDESTE. Anais. Disponível em: <http://cchla.ufrn.br/rmnatal/artigo/artigo21.pdf>. Acesso em: 15 jul 2017.

BERNADELLI, M. L. F. da H. (2010). “Contribuição ao debate sobre o urbano e o rural”. In. SPOSITO, M. E. B. e WHITACKER, A. M. (orgs.). Cidade e campo: relações e contradições entre o urbano e rural. São Paulo, Expressão Popular.

BRASIL (2010). Lei 12.305/2010 de 2 de agosto de 2010. Institui a Política Nacional de Resíduos Sólidos; altera a Lei no 9.605, de 12 de fevereiro de 1998; e dá outras providências. Diário Oficial da República Federativa do Brasil, Brasília, DF, 3 ago 2010. Disponível em: <http://www.planalto. gov.br/ccivil_03/_ato2007-2010/2010/lei//12305.htm>. Acesso em: 20 jan 2017.

CASTELLS, M. e BORJA, J. (1996). A cidade como atores políticos. Novos Estudos, n. 45, pp. 152-166.

CLEMENTINO, M. do M. (2003). A região metropolitana e o Parlamento Comum: a carta dos vereadores da Grande Natal. Cadernos Metrópole. São Paulo, n. 10, pp. 27-54. 
CLEMENTINO, M. L. M. (2016). Regiões metropolitanas no Brasil: visões do presente e do futuro. XIV COLÓQUIO INTERNACIONAL DE GEOCRÍTICA LAS UTOPÍAS Y LA CONSTRUCCIÓN DE LA SOCIEDAD DEL FUTURO BARCELONA. Disponível em: <http://www.ub.edu/geocrit/xiv_livraclementino. pdf>. Acesso em: 28 abr 2016.

CLEMENTINO, M. L. do M. e ALMEIDA, L. S. B. (2015). Construção técnico-política de governança metropolitana. Cadernos Metrópole. São Paulo, v. 17, n. 33, pp. 201-224.

DUARTE, M. C. S. (2015). A laudato si: um novo, necessário e aprofundado olhar sobre a crise socioambiental na sociedade contemporânea. Revista FIDES, v. 6, pp. 20-39. Disponível em: http://www.revistafides.com/ojs/index.php/br/article/viewFile/497/787. Acesso em: 26 mar 2017.

FREY, K. (2012). Abordagens de governança em áreas metropolitanas da América Latina: avanços e entraves. Urbe: Revista Brasileira de Gestão Urbana. v. 4, n. 1.

GOUVÊA, R. G. (2009). Diretrizes para a gestão metropolitana no Brasil. Disponível em: <http://www. scielo.cl/scielo.php?script=sci_arttext\&pid=S0250-71612009000100003>. Acesso em: 26 maio 2016.

GROSTEIN, M. D. (2001). Metrópole e expansão urbana: a persistência de processos "insustentáveis". São Paulo em perspectiva, v. 15, n. 1, pp. 13-19.

GUERRA, S. (2010). A tutela constitucional do meio ambiente no Brasil: do slogan a industrialização suja é melhor que a pobreza limpa até o reconhecimento como direito fundamental. In: XIX CONGRESSO NACIONAL DO CONPEDI. Anais. Florianópolis.

GUERRA, S. e GUERRA, S. (2012). Intervenção estatal ambiental: licenciamento e compensação de acordo com a Lei Complementar no 140/2011. São Paulo, Atlas.

IBGE - Instituto Brasileiro de Geografia e Estatística (2010). Censo Demográfico - 2010. Rio de Janeiro, IBGE.

IPEA - Instituto de Pesquisa Econômica Aplicada (2015). Atlas da vulnerabilidade social nos municípios brasileiros. Brasília, IPEA.

PESSOA, Z. P. (2012). A Metrópole Periférica: identidade e vulnerabilidade socioambiental na Região Metropolitana de Natal-RN/Brasil. Tese de Doutorado. Campinas, Universidade Estadual de Campinas.

RIBEIRO, L. C. Q. e SANTOS JUNIOR, O. A. dos (2007). As metrópoles e a questão social brasileira. Rio de Janeiro, Revan/Fase.

ROLNIK, R. e SOMEKH, N. (2002). Governar as Metrópoles: Dilemas da Recentralização. Cadernos Metrópole. São Paulo, n. 8, pp. 105-117. Disponível em: <https://revistas.pucsp.br/index.php/ metropole/article/view/9253/6865>. Acesso em: 26 maio 2016.

SILVA, J. A. da (2013). Curso de Direito Constitucional Positivo. São Paulo, Malheiros.

SILVEIRA, R. M. da C. e CLEMENTINO, M. do L. M. (2017). Novas Regras, Velhos Entraves: o Desafio da Gestão dos Resíduos Sólidos nos municípios Brasileiros. In: XVII ENANPUR. Anais. São Paulo.

SILVEIRA, R. M. da C.; FERREIRA, A. C. e NUNES, M. M. A. (2017). “Gestão integrada de resíduos sólidos: a busca por soluções pactuadas na Região Metropolitana de Natal - RN". In: EL-DEIR, S. G.; BEZERRA, R. P. L. e AGUIAR, W. J. de (orgs.). Resíduos sólidos: diagnósticos e alternativas para a gestão integrada. Recife, EDUFRPE. 
SOUZA, M. (2000). “Os conceitos de planejamento urbano e gestão urbana (Parte I)". In: SOUZA, M. L. de. Mudar a cidade: uma introdução crítica ao planejamento. Rio de Janeiro, Bertrand Brasil.

VILLAÇA, F. (1997). A delimitação territorial do processo urbano. Disponível em: <http://www. flaviovillaca.arq.br/pdf/intra497.pdf>. Acesso em: 20 mar 2016.

Texto recebido em 30/nov/2017

Texto aprovado em 17/abr/2018 